\title{
Rare Pulmonary Connective Tissue Type Mast Cells Regulate Lung Endothelial Cell Angiogenesis
}

Yue Ren, ${ }^{\star \dagger}$ Yuyan Lyu, ${ }^{\ddagger}$ Jared A. Mereness, ${ }^{\star \S}$ Shumin Wang, ${ }^{\ddagger \mathbb{\top}}$ Jinjiang Pang, ${ }^{\ddagger \uparrow}$ and Thomas J. Mariani ${ }^{\star}$

From the Division of Neonatology and Pediatric Molecular and Personalized Medicine Program, ${ }^{*}$ the Departments of Biology ${ }^{\dagger}$ Pediatrics, ${ }^{\ddagger}$ and Biomedical Genetics, ${ }^{\S}$ and the Aab Cardiovascular Research Institute, ${ }^{\Uparrow}$ University of Rochester, Rochester, New York

\author{
Accepted for publication \\ April 27, 2020. \\ Address correspondence to \\ Thomas J. Mariani, Ph.D., Pe- \\ diatric Molecular and Personal- \\ ized Medicine Program, \\ Division of Neonatology, Uni- \\ versity of Rochester Medical \\ Center, 601 Elmwood Ave., \\ Box 850, Rochester, \\ NY 14642. E-mail: tom \\ mariani@urmc.rochester.edu.
}

\begin{abstract}
Within the human lung, mast cells typically reside adjacent to the conducting airway and assume a mucosal phenotype $\left(M C_{T}\right)$. In rare pathologic conditions, connective tissue phenotype mast cells $\left(M C_{T C} S\right)$ can be found in the lung parenchyma. $M C_{T C} S$ accumulate in the lungs of infants with severe bronchopulmonary dysplasia, a chronic lung disease associated with preterm birth, which is characterized by pulmonary vascular dysmorphia. The human mast cell line (LUVA) was used to model $\mathrm{MC}_{\mathrm{TC}} \mathrm{S}$ or $M C_{T} S$. The ability of $M C_{T C}$ to affect vascular organization during fetal lung development was tested in mouse lung explant cultures. The effect of $M_{\mathrm{TC}_{\mathrm{C}} S}$ on in vitro tube formation and barrier function was studied using primary fetal human pulmonary microvascular endothelial cells. The mechanistic role of $M C_{T C}$ proteases was tested using inhibitors. $M C_{T C}$ LUVA but not $M C_{T} L U V A$ was associated with vascular dysmorphia in lung explants. In vitro, the addition of $M_{C_{T C} L U V A}$ potentiated fetal human pulmonary microvascular endothelial cell interactions, inhibited tube stability, and disrupted endothelial cell junctions. Protease inhibitors ameliorated the ability of $M C_{T C} L U V A$ to alter endothelial cell angiogenic activities in vitro and ex vivo. These data indicate that $\mathrm{MC}_{\mathrm{TC}} \mathrm{S}$ may directly contribute to disrupted angiogenesis in bronchopulmonary dysplasia. A better understanding of factors that regulate mast cell subtype and their different effector functions is essential. (Am J Pathol 2020, 190: 1763-1773; https://doi.org/10.1016/j.ajpath.2020.04.017)
\end{abstract}

Bronchopulmonary dysplasia (BPD) is the most common pulmonary disease because of premature birth, resulting in 10,000 BPD cases annually in the United States alone. ${ }^{1-4} \mathrm{~A}$ $\mathrm{BPD}$ diagnosis increases the risk of long-term pulmonary morbidity, including recurrent wheezing and asthma. ${ }^{3,5-7}$ Multiple pathologic symptoms are associated with BPD, including alveolar simplification, disrupted vasculogenesis, altered inflammation, and oxygen toxicity. ${ }^{1-4,6-10}$

It is widely believed that mast cells (MCs) arise from the common myeloid progenitor via the basophil/MC progenitor as MC progenitors. ${ }^{1-13} \mathrm{MC}$ progenitors are released from the bone marrow and enter target tissues, where they mature under the instructive signals of their local microenvironment. $^{11,14}$ Consequently, MCs from various tissues differ phenotypically from each other. Distinct populations are named [mucosal $\mathrm{MCs}\left(\mathrm{MC}_{\mathrm{T}} \mathrm{s}\right)$ and connective tissue MCs $\left.\left(\mathrm{MC}_{\mathrm{TC}} \mathrm{S}\right)\right]$ based on the location in which they were first identified. It was later discovered that the two $\mathrm{MC}$ subtypes express different proteases. ${ }^{14-19} \mathrm{MC}_{\mathrm{TC}} \mathrm{S}$ express two tryptases (TPSAB1 and TPSB2), carboxypeptidase A3 (CPA3), and chymase 1 (CMA1), whereas $\mathrm{MC}_{\mathrm{T}} \mathrm{S}$ express only tryptases. ${ }^{16-18,20}$ In healthy human lungs, $\mathrm{MC}_{\mathrm{T}} \mathrm{S}$ are found in the trachea and large airways. ${ }^{11,14,21,22}$

A significant enrichment of MC-specific genes in BPD has been previously identified. ${ }^{10}$ Immunohistochemical staining of lung tissues confirmed a 50-fold increase in the accumulation of CMA-expressing $\mathrm{MC}_{\mathrm{TC}} \mathrm{s}$ in lungs with BPD. ${ }^{10}$ $\mathrm{MC}_{\mathrm{TC}} \mathrm{S}$ are rare in human lungs but are found in asthma with high Th2 cell counts and in chronic obstructive pulmonary disease. ${ }^{23-27}$ The accumulation of $\mathrm{MC}_{\mathrm{TC}}$ s in a genetic model with BPD-like pathologic features has also been reported. ${ }^{10}$ Another report found that MC accumulation in a model of BPD was associated with neonatal supraphysiologic oxygen exposure and that MC-deficient mice are partially

\footnotetext{
Supported by Pediatric Molecular and Personalized Medicine Program (T.J.M.).

Disclosures: None declared.
} 
protected from pathologic findings. ${ }^{22}$ This study did not provide insight into the phenotype of the MCs involved.

Although several studies describe disorganization of the pulmonary microvasculature in BPD, limited studies have explored the cause of this impairment. ${ }^{3,9,28,29}$ Pulmonary vasculature development starts at embryonic day (ED) 9.5 in mice or gestational week 4 in humans. ${ }^{3,30,31}$ The preexisting loose network of endothelium begins to arrange around the distal airspaces during the canalicular stage through the process of angiogenesis and vasculogenesis. ${ }^{9,31}$ Capillaries are then embedded in the primary septa during the saccular phase and continue to expand and mature. ${ }^{9,31}$ Premature infants born at 24 to 27 weeks of gestation are in the late canalicular stage (ED 16.5 to 17.5 in mice), which is also the period of high BPD risk. ${ }^{2-4,9}$

We hypothesized that $\mathrm{MC}_{\mathrm{TC}}$ accumulation contributes to the impaired vascularization during early lung development in BPD. We found that human $\mathrm{MC}_{\mathrm{TC}} \mathrm{S}$ but not $\mathrm{MC}_{\mathrm{T}} \mathrm{S}$ significantly disrupt vascular organization in mouse fetal lung explants and human fetal lung microvascular endothelial cells. Mechanistically, $\mathrm{MC}_{\mathrm{TC}} \mathrm{S}$ enhance initiation of endothelial cell-cell interactions but destabilize mature endothelial cell tight junctions.

\section{Materials and Methods}

\section{Cell Culture}

LUVA (Kerafast, Boston, MA), an immortalized human MC line, derived from an 8-week-old CD34 ${ }^{+}$mononuclear cell culture, ${ }^{32}$ were maintained in StemPro34 (Gibco, Carlsbad, CA) supplied with $1 \%$ penicillin/streptomycin and 200 $\mathrm{mmol} / \mathrm{L}$ L-glutamine. LUVAs express all three MC-specific proteases, including TPSAB1/TPSB2, CMA1, and CPA3, under these culture conditions.

Fetal human pulmonary microvascular endothelial cells (feHPMVCs; ScienCell, Carlsbad, CA) were maintained in endothelial cell growth medium with $1 \%$ penicillin/streptomycin and 5\% fetal bovine serum. All experiments were conducted with feHPMVCs within 5 passages.

Human bronchial epidermal (16HBE) cells, a SV40 transformed human bronchial epithelial cell line, were grown using Dulbecco's modified Eagle medium supplemented with $10 \%$ fetal bovine serum, $1 \%$ penicillin/streptomycin, $1 \%$ nonessential amino acids, sodium pyruvate, and HEPES buffer. $16 \mathrm{HBE}$ cells were cultured at $37^{\circ} \mathrm{C}$ in a humidified incubator containing $5 \% \mathrm{CO}_{2}$. The cells were allowed to form tight junctions and then differentiated at air-liquid interface.

All animal-related experiments are approved by the University Committee on Animal Resources (University of Rochester Medical Center, Rochester, NY) under protocol 2008-043E.

\section{Induced $M C_{T} S$}

16HBE cells were seeded on the apical surface of a 12-well transwell (Corning, Corning, NY) and allowed to reach confluence. The epithelial cells were allowed to form tight junctions, then differentiated at air-liquid interface for 2 days. LUVAs were then seeded at 0.25 million cells $/ \mathrm{mL}$ in the basal chamber. The phenotype of the co-cultured MCs were assessed by quantitative RT-PCR (RT-qPCR) analysis of the expression levels of TPSAB1, TPSB2, CMA1, and $C P A 3$ (Supplemental Figure S1A). Changes in CMA1 and phosphorylated CPA3 were then confirmed using Western blot analysis. Western blot (Supplemental Figure S1B) confirmed the absence of CMA1 and CPA3 in co-cultured LUVAs.

\section{Ex Vivo Angiogenesis Experiments}

Timed mating of wild-type C57BL/6J mice was performed. At ED 16, the dam was sacrificed and mouse embryos were dissected from the uterine horns. The lung lobes of ED 16 mice were carefully dissected, washed twice with Dulbecco's phosphate-buffered saline, and then placed on the apical surface of fibronectin (F1141, 2 mg; Sigma-Aldrich, St. Louis, MO) precoated transwells. The individual lung lobes were allowed to attach for 30 minutes at $37^{\circ} \mathrm{C}$ and cultured at $37^{\circ} \mathrm{C}$ for 48 hours in the absence or presence of 30,000 feHPMVC-primed $\mathrm{MC}_{\mathrm{TC}} / \mathrm{MC}_{\mathrm{T}}$ LUVAs in the bottom chamber.

\section{In Vitro Angiogenesis Experiments}

The 96-well tissue culture plates were coated with Matrigel (Corning) on ice and allowed to polymerize at $37^{\circ} \mathrm{C}$ for 30 minutes. feHPMVCs were then seeded at 2000 cells per well alone (control) and mixed with $5000 \mathrm{MC}_{\mathrm{TC}} \mathrm{S}$ or 5000 $\mathrm{MC}_{\mathrm{T}} \mathrm{s}$. The cells were imaged for 12 hours using an inverted phase-contrast microscope. The images were processed and quantified for tube complexity (number of mesh) using ImageJ software version 1.52a(NIH, Bethesda, MD; http:// imagej.nih.gov/ij).

\section{Transendothelial Electrical Resistance}

feHPMVC cultures were seeded at 100,000 cells per well in fibronectin-coated inserts of a 12-well transwell plate and allowed to grow to confluence. The cells were allowed to form tight junctions until the transendothelium electrical resistance (TEER) was $>200 \mathrm{~m} \Omega$. $\mathrm{MC}_{\mathrm{TC}} \mathrm{S}$ or $\mathrm{MC}_{\mathrm{T}} \mathrm{S}$ were added at 20,000 cells per well to the bottom well, and TEER was measured after 12 hours with an epithelial volt/ohm meter voltahmmeter (World Precision Instruments, Sarasota, FL) equipped with a pair of Chopstick Electrode Sets (World Precision Instruments). ${ }^{33}$

\section{Paracellular Endothelial Permeability Assay}

feHPMVC cultures were seeded at 100,000 cells per well on fibronectin-coated inserts of a 12-well transwell plate and allowed to establish tight junctions, as above. $\mathrm{MC}_{\mathrm{TC}} \mathrm{s}$ or 
$\mathrm{MC}_{\mathrm{T}} \mathrm{s}$ were added at 20,000 cells per well to the bottom well, respectively. Then $100 \mu \mathrm{L}$ of $300-\mu \mathrm{g} / \mathrm{mL}$ fluorescein isothiocyanate-dextran $\quad(10,000 \mathrm{~mol}$. wt.; Invitrogen, Carlsbad, CA) was added to the media in the apical chamber. The maximum possible permeability was established by adding fluorescein isothiocyanate-dextran to fibronectincoated transwells without cells. After 6 hours, $100 \mu \mathrm{L}$ of media was harvested from the basal chamber, and fluorescence intensities were quantified on a VICTOR2 1420 Multilabel Counter using Wallac software (PerkinElmer Life Sciences, Waltham, MA). The fluorescent intensities from all samples were normalized to the fluorescent intensity of the maximum possible permeability.

\section{Inhibitor Treatment}

For inhibitor treatment, $200 \mu \mathrm{g} / \mathrm{mL}$ of soybean-derived serine protease inhibitor (VWR AMRESCO, K213-1G; Avantar, Radnor, PA) or $30 \mu \mathrm{mol} / \mathrm{L}$ chymostatin (MP Biomedicals, Irvine, CA) was applied to LUVAs for 1 hour. Before adding to endothelial cells, the LUVA cells were washed with Dulbecco's phosphate-buffered saline and added to the in vitro angiogenesis experiments.

\section{RT-qPCR}

Quantitative RT-PCR (RT-qPCR) was performed using predeveloped noncommercial assays (PrimerBank, http://pga. mgh.harvard.edu/primerbank, last accessed June 9, 2016). Briefly, RNA samples were isolated using the Absolutely RNA Microprep kit (Agilent, Santa Clara, CA). Reverse transcription reaction was performed using the Script cDNA Synthesis Kit (BioRad, Hercules, CA), and cDNA samples were run in duplicate using Power SYBR Green Master Mix (Applied Biosystems, Foster City, CA). The results were analyzed using the $\Delta \Delta \mathrm{CT}$ method.

\section{Western Blot Analysis}

To confirm MC phenotype, LUVAs were snap frozen in liquid nitrogen and lysed with radioimmunoprecipitation assay buffer (Thermo Fisher Scientific, Waltham, MA) with a protease inhibitor cocktail (Thermo Fisher Scientific) on ice and then boiled at $100^{\circ} \mathrm{C}$ for 10 minutes. To detect MC proteases in the conditioned media, the media was snap frozen with liquid nitrogen and then boiled for 10 minutes. Samples were then resolved on SDS-PAGE and transferred onto polyvinylidene difluoride membranes (BioRad). Membranes were blocked by incubating in 5\% (w/v) molecular grade blocker (BioRad) in Tris-buffered saline with Tween-20 for 1 hour at room temperature. MC-specific proteases were detected by overnight incubation in antibodies (1:1000 dilution) against tryptase- $\beta_{2}$ (Thermo Fisher Scientific), CMA1 (MA5-11717; Thermo Fisher Scientific), and CPA3 (16236-1-AP; Proteintech). Finally, membranes were incubated for 1 hour with a mouse anti-rabbit $\operatorname{IgG}$ horseradish peroxidase (Santa Cruz Biotechnology, Dallas, $\mathrm{TX}$ ) or goat anti-mouse IgG horseradish peroxidase (Santa Cruz Biotechnology) antibody and developed using Supersignal West Pico PLUS kit (Thermo Fisher Scientific).

\section{Lectin Staining}

Ex vivo cultured E16.5 C57BL/6J mouse lungs were fixed in 4\% paraformaldehyde (Thermo Fisher Scientific). The fixed lobes were then cleared using a protocol adapted from CUBIC $\mathrm{Cancer}^{3}$ and stained with tetramethylrhodamineconjugated isolectin-IB4 (L5264; Sigma-Aldrich) and DAPI (D3571; Invitrogen). The samples were then mounted and visualized using a multiphoton microscope (FVMPERS; Olympus, Tokyo, Japan).

feHPMVCs monolayers on transwells were fixed using icecold $10 \%$ neutral buffered formalin (Thermo Fisher Scientific). The fixed feHPMVCs were then stained with DyLight 594-labeled Ulex Europaeus Agglutinin I (DL-1067, 1:1000 dilution; Vector Laboratories, Burlingame, CA).

\section{Immunofluorescent Staining}

Ex vivo cultured E16.5 C57BL/6J mouse lungs were fixed in 4\% paraformaldehyde (Thermo Fisher Scientific). The fixed lobes were then cleared using a protocol adapted from CUBIC Cancer ${ }^{34}$ and stained with Von Willebrand factor primary antibodies (GA52761-2, 1:250 dilution; Dako, Glostrup, Denmark). Primary antibody staining was then detected by Texas Red-conjugated goat-anti-rabbit secondary antibody (T6391, 1:1000 dilution; Life Technology, Carlsbad, CA). DAPI was used to stain nuclei. The samples were then mounted and visualized using a multiphoton microscope (FVMPE-RS, Olympus).

feHPMVC monolayers on transwells were fixed using icecold 10\% neutral buffered formalin (Thermo Fisher Scientific). The fixed feHPMVCs were then stained with mouse anti-human CDH5 antibody (555661, 1:250 dilution; BD Pharmingen, San Diego, CA). Nucleus were stained with DAPI. The samples were then visualized using a DM5500B fluorescent microscope (Leica, Wetzlar, Germany).

\section{Three-Dimensional Reconstruction and Quantification}

Three-dimensional reconstruction was performed using segmentation function with Amira software version 6.5 (Thermo Fisher Scientific). The reconstructed surfaces were visualized with surface view function. The volumes of the reconstructed structure were listed in the material statistics. The relative vessel volume was determined by normalizing the volume of IsolectinB4 to the volume of DAPI in each field.

\section{Statistical Analysis}

Data that involved pairwise comparison (such as quantitative PCR, Western blot, relative vessel volume, growth 
phase or decay phase time, TEER, or paracellular vascular permeability) were tested using a paired $t$-test. The tube complexity overtime and of branches in in vitro angiogenesis experiment were tested using the $\chi^{2}$ test. $P<0.05$ was considered to be statistically significant.

\section{Results}

\section{$\mathrm{MC}_{\mathrm{TC}} \mathrm{S}$ Induce Fetal Lung Microvascular Dysmorphism ex Vivo}

Previous studies described the accumulation of $\mathrm{MC}_{\mathrm{TC}} \mathrm{S}$ in $\mathrm{BPD}^{10}$ and mouse models of BPD-like pathologic findings. $^{22}$ Disruption and deficiency in lung parenchyma microvasculature have been well described in BPD. ${ }^{2,3,9}$ Therefore, this study tested whether there was a direct link between the presence of MCs and microvascular dysmorphia during fetal lung development at a stage when BPD risk is highest. Fetal lung tissues were isolated from ED 16.5 mice and placed in culture for 48 hours in the absence or presence of human MCs. Lung microvasculature (Figure 1) was compared by reconstructing the thee-dimensional structure of DAPI-stained nuclei and isolectin B4 staining vessels. A significant reduction was observed in the relative vessel volume when mouse lung tissues were cultured in the presence of $\mathrm{MC}_{\mathrm{TC}} \mathrm{S}(t$-test $P=0.0069)$ (Figure 1C). Lungs co-cultured with $\mathrm{MC}_{\mathrm{TC}} \mathrm{S}$ also had a marked dysmorphism, featuring reduced connection among endothelial cells (Figure 1B). Importantly, when mouse lung tissues were cultured in the presence of $\mathrm{MC}_{\mathrm{T}} \mathrm{s}$ (Figure 1, A and $\mathrm{B}$ ), vascular structure was normal (Figure 1B). These results were confirmed by Von Willebrand factor staining of vascular endothelial cells (Supplemental Figure S2). This study tested whether these observations were associated with the presence of cell death but low levels of apoptotic cells were found in all conditions (Supplemental Figure S3, A and B). Interestingly, RT-qPCR analysis found no significant loss of pulmonary endothelial cell marker gene expression (Supplemental Figure S3C). These data suggest that $\mathrm{MC}_{\mathrm{TC}}$-induced vascular dysmophism may be due to alterations in endothelial cell capacity to form vessels.

\section{$\mathrm{MC}_{\mathrm{TC}} \mathrm{S}$ Directly Disrupt feHPMVC Tube Formation}

The effects of $\mathrm{MC}_{\mathrm{TC}} \mathrm{S}$ on vascular structure were confirmed by testing their ability to directly alter feHPMVC tube formation. feHPMVCs were allowed to form tubes during a 12-hour period in the absence or presence of MCs. Hourly imaging quantified the initiation and stabilization of tubular structures (Figure 2). Co-culture of feHPMVCs with $\mathrm{MC}_{\mathrm{TC}} \mathrm{S}$ was associated with notable differences in tubular structures ( $\chi^{2}$ test $P<0.0001$ ) (Figure 2$)$. When co-cultured with $\mathrm{MC}_{\mathrm{TC}} \mathrm{S}$, the rate of developing tubular complexity was a mean of 1.8 hours faster (2.87 versus 5.25 hours, $t$-test $P<0.0001$ ) when compared with feHPMVCs cultured on matrigel alone (Figure 3C). The stability of tubular

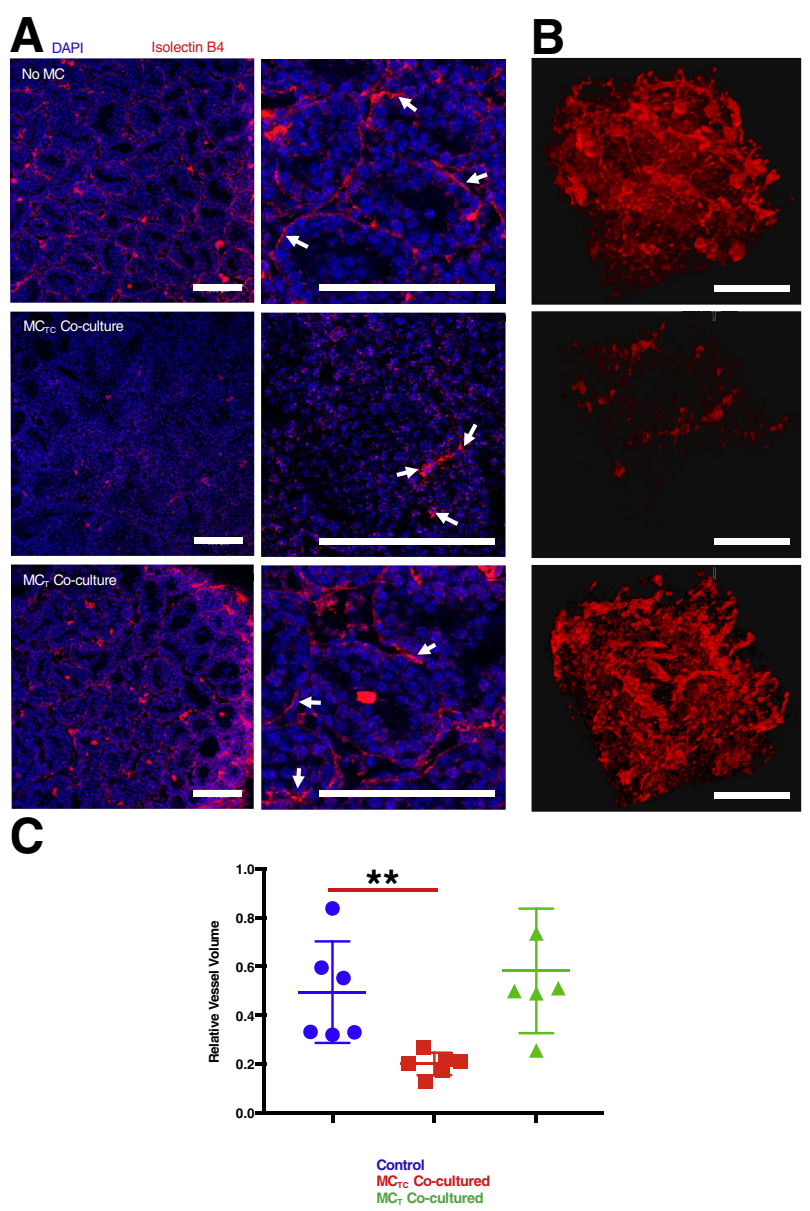

Figure 1 Connective tissue phenotype mast cells $\left(M C_{T C} S\right)$ cause microvascular dysmorphism in the developing lung. A: Representative images of embryonic mouse lung tissue explant cultured for 48 hours alone [no mast cells (MCS) (control)] and with $\mathrm{MC}_{\mathrm{TC}} \mathrm{S}$ or mucosal phenotype mast cells $\left(M C_{T} s\right)$. The microvasculature was stained with tetramethylrhodamineconjugated isolectin B4 (red), and nuclei were stained with DAPI (blue). Arrows indicate endothelial cells stained with Isolectin B4. B: Representative three-dimensional reconstructed microvasculature showing the inset region. C: Quantification of total volume of vasculature relative to the total nuclear volume in each condition. $n=6$ (and in triplicates). ${ }^{* *} P<0.01$ ( $t$-test). Scale bars $=100 \mu \mathrm{m}$.

structures in $\mathrm{MC}_{\mathrm{TC}}$ co-cultured samples was also disrupted compared with feHPMVCs cultured on matrigel alone (Figure 2). The time at which the cultures reached a $70 \%$ reduction in complexity was reduced by a mean of 4.5 hours faster (11 versus 6.75 hours, $t$-test $P=0.0046$ ). feHPMVCs co-cultured on matrigel with $\mathrm{MC}_{\mathrm{T}} \mathrm{s}$ had no significant differences in tube formation, including in both the initiation and stabilization phases.

\section{$\mathrm{MC}_{\mathrm{TC}} \mathrm{S}$ Promote Initiation but Disrupt Maintenance of Endothelial Cell-Cell Interactions}

The number of cells at individual cell-cell junctions during the initiation of feHPMVC tube formation (2 hours) was carefully quantified. During this initial phase, feHPMVCs 

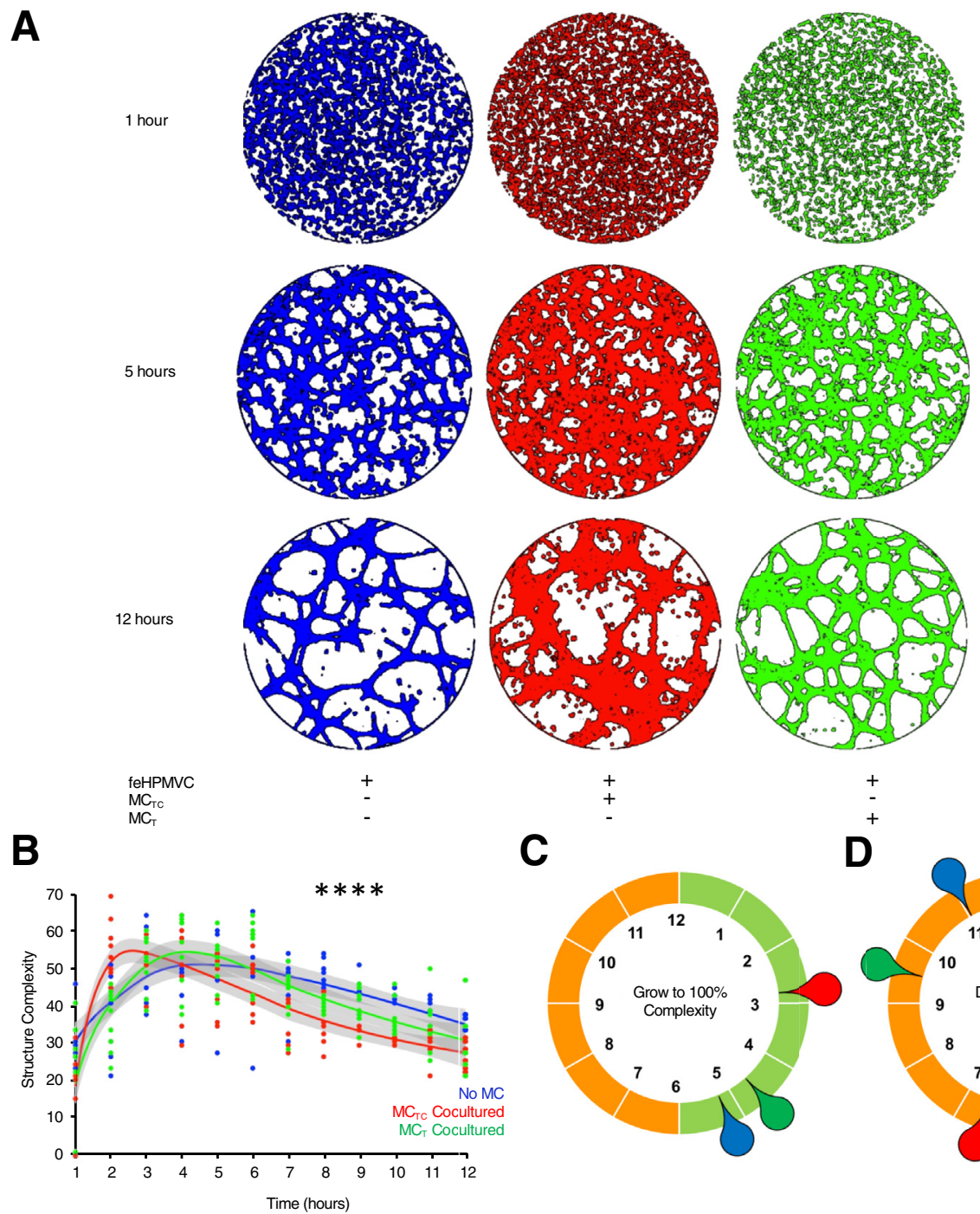

C

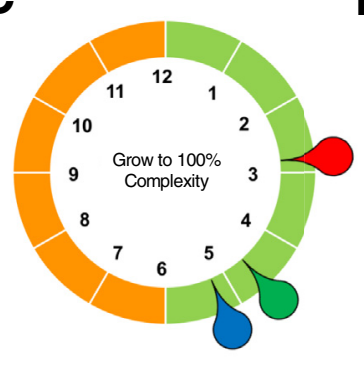

D

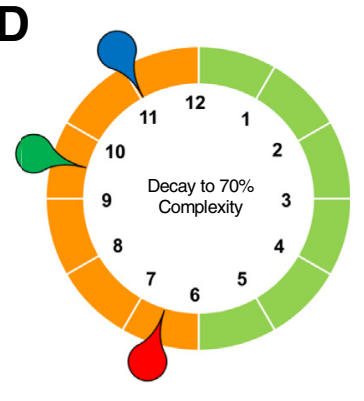

Figure 2 Connective tissue phenotype mast cells $\left(M C_{T C} S\right)$ disrupt endothelial cell tube formation. A: Representative, color-enhanced images of fetal human pulmonary microvascular endothelial cells (feHPMVCs) undergoing tube morphogenesis when cultured for 12 hours alone (blue) and with $M_{C_{T C}}$ (red) or mucosal phenotype mast cells $\left(\mathrm{MC}_{\mathrm{T}} \mathrm{s}\right.$ ) (green). B: Quantification of tube complexity (Materials and Methods) defined each hour during tube formation. C: Graphical representation of the mean time (in hours) needed to reach maximum tube structure complexity for each condition. D: Graphical representation of the mean time (in hours) needed for tube structures to regress to $70 \%$ of their maximum complexity. $n=3$ (and in triplicates). ${ }^{* * *} P<0.0001$ control versus $M C_{\text {TC }}$ co-culture $\left(\chi^{2}\right.$ test).

appear to elongate, migrate, and form multicellular nodes. These nodes are composed of two to five individual endothelial cells, with most nodes containing three cells (Figure 3A). When feHPMVCs were cultured with $\mathrm{MC}_{\mathrm{TC}} \mathrm{S}$, a significant shift in the distribution $\left(\chi^{2}\right.$ test $\left.P<0.0001\right)$ of endothelial cells per node (Figure $3 \mathrm{~B}$ ) was observed. The shift included an increase in the number of nodes with more endothelial cells, with a significant increase in the number of nodes that contained five branches (13\% versus $35 \%$, $P=0.0012)$. No differences in the distribution of the number of cells that formed nodes was observed in feHPMVCs when co-cultured with $\mathrm{MC}_{\mathrm{T}} \mathrm{s}$.

Although $\mathrm{MC}_{\mathrm{TC}} \mathrm{S}$ appeared to promote initiation of endothelial cell-cell junction formation in nodes, they also were associated with an inability to maintain tube structures. Therefore, this study then tested whether $\mathrm{MC}_{\mathrm{TC}} \mathrm{S}$ inhibited the stability of endothelial cell-cell interactions. feHPMVC monolayers were grown to confluence in the upper chamber of a transwell and assayed for TEER and pericellular permeability in the absence or presence of MCs placed in the bottom chamber. TEER was significantly reduced in feHPMVC monolayers that contained $\mathrm{MC}_{\mathrm{TC}}$ ( $t$-test $P<0.0001$ ) (Figure 4B). Similarly, pericellular permeability was significantly increased in feHPMVC monolayers that contained $\mathrm{MC}_{\mathrm{TC}} \mathrm{S}$ ( $t$-test $P<0.0006$ ) (Figure $4 \mathrm{~A}$ ). $\mathrm{MC}_{\mathrm{T}} \mathrm{s}$ had no effects on feHPMVC TEER or permeability. In addition, immunostaining for $\mathrm{CDH} 5$ revealed a drastic and selective loss of cell-cell junctions in the presence of $\mathrm{MC}_{\mathrm{TC}} \mathrm{S}$ but not $\mathrm{MC}_{\mathrm{T}} \mathrm{s}$ (Figure $4 \mathrm{C}$ ). 
A

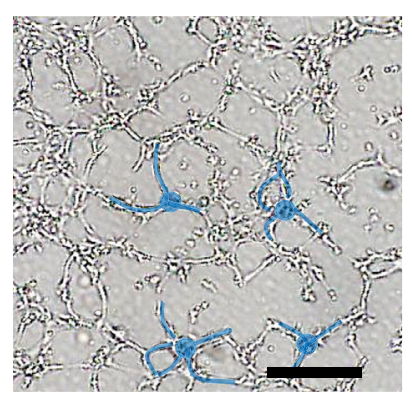

B

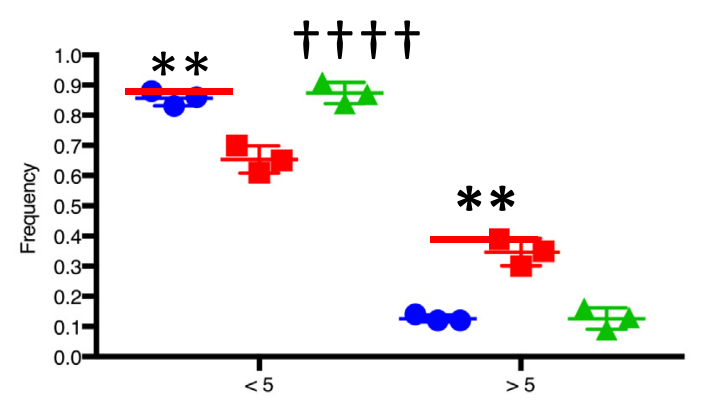

$\mathrm{MC}_{\mathrm{TC}}$ co-culture

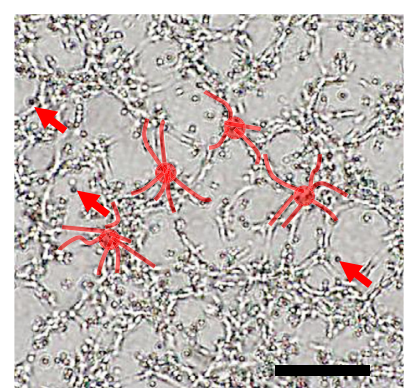

$\mathrm{MC}_{\mathrm{T}}$ co-culture

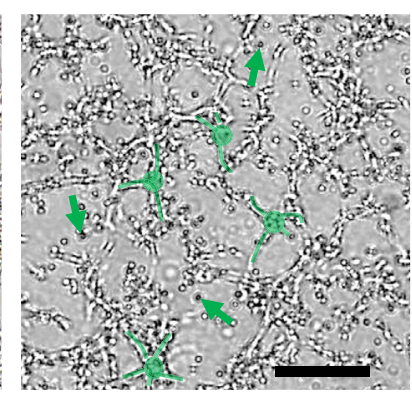

C

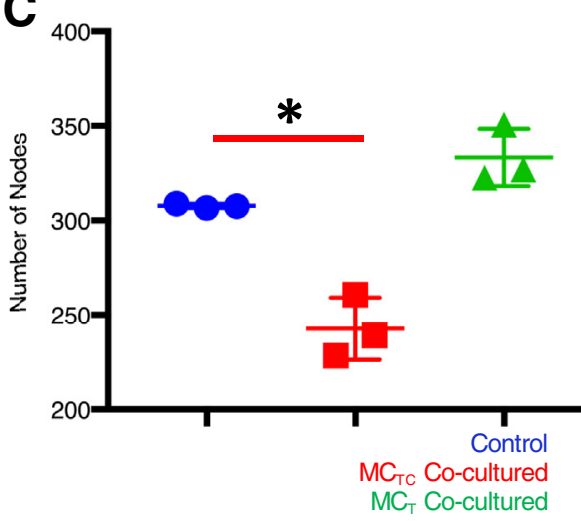

Figure 3 Connective tissue phenotype mast cells $\left(\mathrm{MC}_{\mathrm{TC}} \mathrm{S}\right)$ promote the initiation of endothelial cell-cell contacts during tube formation. A: Representative, colorenhanced images of fetal human pulmonary microvascular endothelial cells (feHPMVCs) undergoing tube morphogenesis when cultured for 2 hours alone and with $M C_{T C} S$ or mucosal phenotype mast cells $\left(M C_{T} S\right)$. Representative feHPMVC cell-cell junctions are highlighted. No MC (control) is labeled in blue, $\mathrm{MC}_{\mathrm{TC}}$ co-culture is labeled in red, and $M C_{T}$ co-culture is labeled in green. Red arrows indicate representative $M C_{T C}$ human mast cell lines (LUVAs); green arrows, representative $M C_{T}$ LUVAs. B: Quantification of the frequency of cell-cell junctions containing $<5$ cells or $\geq 5$ cells in each condition. C: Quantification of the total number of junctions in each condition. $n=3$ (and in triplicates). ${ }^{*} P<0.05,{ }^{* *} P<0.01$ (t-test); ${ }^{\dagger}+\dagger \uparrow<0.0001$ versus control $\left(\chi^{2}\right.$ test). Scale bars $=500 \mu \mathrm{m}$.

\section{CMA Activity Is Necessary for the Vasculodisruptive Effects of $M C_{T C}$}

We hypothesized the MC-specific serine proteases, including tryptase (tryptase- $\alpha / \beta_{1}$ and tryptase- $\beta_{2}$ ) and CMA1 played an important role in the vasculodisruptive effects we identified. Therefore, this study analyzed the effects of two different serine protease inhibitors, soybean trypsin inhibitor or chymostatin, on the ability of $\mathrm{MC}_{\mathrm{TC}} \mathrm{S}$ to affect endothelial cell tube formation in vitro (Figure 5). Soybean trypsin inhibitor pretreatment of $\mathrm{MC}_{\mathrm{TC}} \mathrm{S}$ completely blocked the accelerated initiation of feHPMVC tube formation (Figure 5) and the increased instability of feHPMVC tube complexity (Figure 5). Chymostatin pretreatment of $\mathrm{MC}_{\mathrm{TC}} \mathrm{S}$ completely blocked the accelerated initiation of feHPMVC tube formation (Figure 5) and
A

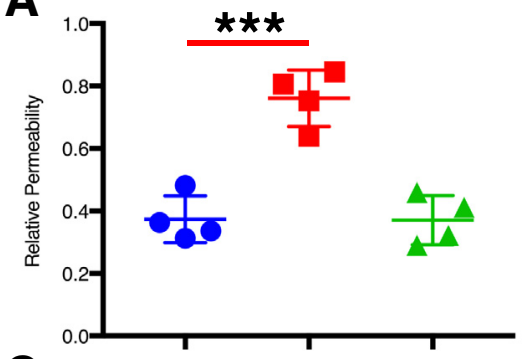

C

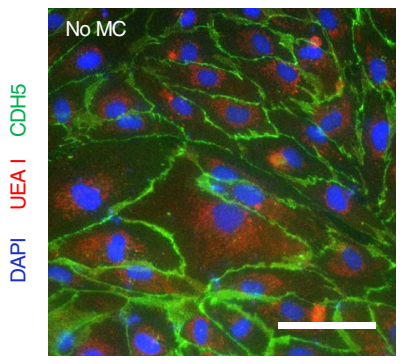

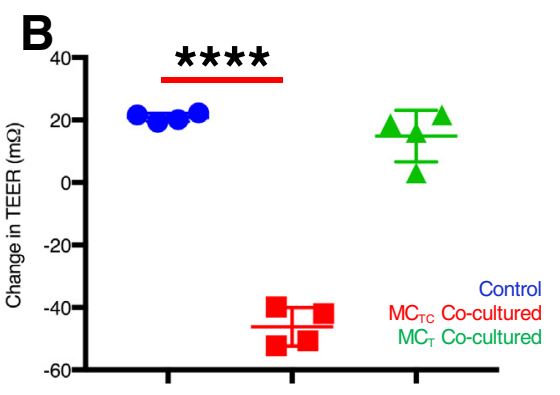

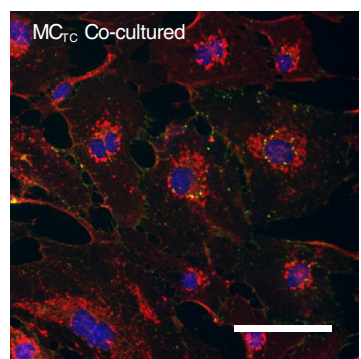

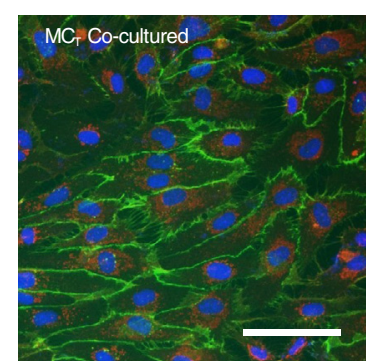

Figure 4 Connective tissue phenotype mast cells $\left(M C_{T C} S\right)$ destabilize endothelial cell-cell junctions. A: Quantification of paracellular permeability of fetal human pulmonary microvascular endothelial cell (feHPMVC) monolayer alone (control; blue) and with $M_{\mathrm{TC}} \mathrm{S}$ (red) or mucosal phenotype mast cells $\left(M C_{T} S\right.$; green). B: Quantification of transendothelial electrical resistance (TEER) in confluent cultures of feHPMVC monolayers alone (control) (blue) and with $\mathrm{MC}_{\mathrm{TCS}}$ (red) or $M_{T} S$ (green). C: Representative images of feHPMVC monolayers in each condition indicated. Cell-cell contacts are visualized by staining for CDH5 (green), and endothelial cell surface glycoprotein (UEA1) and nuclei are visualized by DAPI. $n=4$ (and in triplicates). ${ }^{* * *} P<0.001$ $* * * * P<0.0001$ (t-test). Scale bars $=100 \mu \mathrm{m}$. 

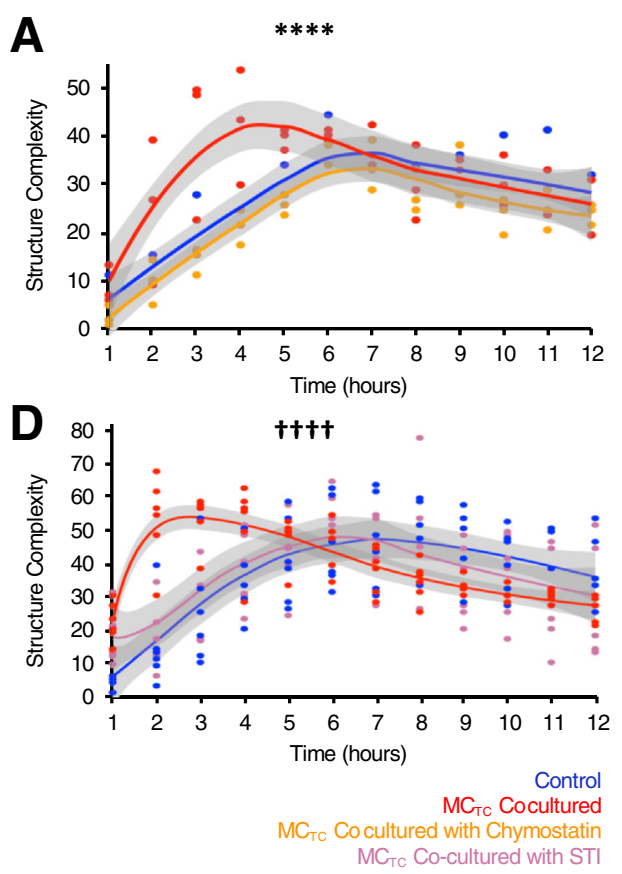

B

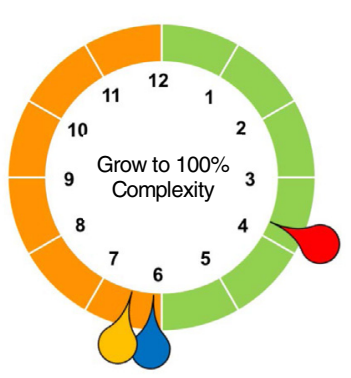

E

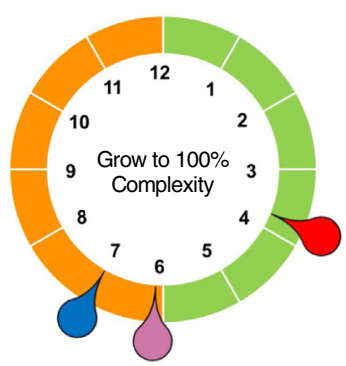

C

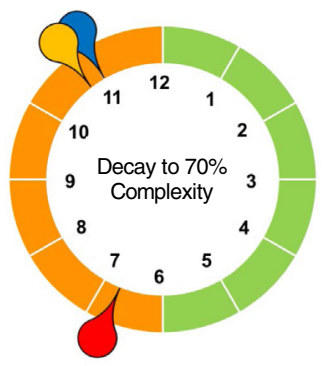

$\mathbf{F}$

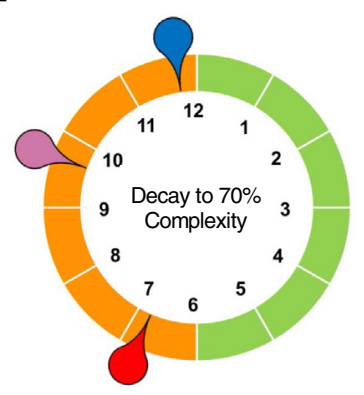

Figure 5 Serine protease inhibition protects against disrupted endothelial cell tube formation. Fetal human pulmonary microvascular endothelial cells (feHPMVCS) were allowed to undergo tube morphogenesis for 12 hours alone (control; blue) and with connective tissue phenotype mast cells (MC $C_{T C} S$; red) or with mucosal phenotype mast cells $\left(\mathrm{MC}_{\mathrm{TC}} \mathrm{S}\right)$ pretreated with soybean derived trypsin inhibitor (STI; yellow; $\mathbf{A}-\mathbf{C}$ ) or chymostatin (purple; D-F). A and $\mathbf{D}$ : Quantification of tube complexity (Materials and Methods) defined each hour during tube formation. B and E: Graphical representation of the mean time (in hours) needed to reach maximum tube structure complexity for each condition. C and F: Graphical representation of the mean time (in hours) needed for tube structures to regress to $70 \%$ of their maximum complexity. $n=3$ (and in triplicates). ${ }^{* \star * *} P<0.0001$ control versus chymostatin treated ( $\chi^{2}$ test); ${ }^{\dagger \dagger \dagger} P<0.0001$ control versus STI treated $\mathrm{MC}_{\mathrm{TC}}$ co-culture ( $\chi^{2}$ test).

partially but significantly blocked the increased instability of feHPMVC tube complexity (Figure 5, D and F). These data suggest that broad inhibition of MC proteases (by soybean trypsin inhibitor) or preferential inhibition of CMA (by chymostatin) significantly blocks the ability of $\mathrm{MC}_{\mathrm{TC}} \mathrm{S}$ to after in vitro endothelial cell angiogenesis.

This study next examined whether chymostatin treatment blocked the ability of $\mathrm{MC}_{\mathrm{TC}} \mathrm{S}$ to disrupt vascular structures in embryonic lung tissue ex vivo. Again, vascular structures in ED 16.5 mouse lung tissue were visually disrupted when cultured in the presence $\mathrm{MC}_{\mathrm{TC}}$ for 48 hours (Figure 6, $\mathrm{A}-\mathrm{C}$ ), including a quantitative reduction in tissue vessel volume (Figure $6 \mathrm{D}$ ). However, when $\mathrm{MC}_{\mathrm{TC}}$ s were pretreated in chymostatin, their ability to disrupt vascular structures was significantly attenuated (Figure 6).

\section{Discussion}

Prior studies have revealed MCs are heterogeneous, with molecular phenotypes defined by their tissue environment. ${ }^{16-20}$ Commonly acknowledged MC subtypes include $\mathrm{MC}_{\mathrm{TC}} \mathrm{S}$ and $\mathrm{MC}_{\mathrm{T}} \mathrm{S}$, which are classified predominantly based on their protease composition. ${ }^{17-19}$ Although MCs occupy the lung and upper airways, they commonly assume a $\mathrm{MC}_{\mathrm{T}}$ phenotype. $\mathrm{MC}_{\mathrm{TC}} \mathrm{S}$ are rare in the distal lung and typically only found in individuals with chronic obstructive pulmonary disease or refractory/severe asthma. ${ }^{11,14,18,21,22,24,26,35,36}$ Despite the potential for distinct MC phenotypes to have distinct functions, the pathophysiologic effects of the presence of $\mathrm{MC}_{\mathrm{TC}} \mathrm{S}$ in the lung are not clear. MCs, particularly $\mathrm{MC}_{\mathrm{TC}} \mathrm{S}$, accumulate in the lungs of infants with severe BPD. ${ }^{10}$ The goal of this study was to understand the possible consequences of $\mathrm{MC}_{\mathrm{TC}}$ accumulation in the BPD lung parenchyma. Because parenchymal vascular abnormalities are a cardinal feature of $\mathrm{BPD}$, this study tested whether $\mathrm{MC}_{\mathrm{TC}} \mathrm{S}$ could directly disrupt the formation of the parenchymal vasculature, which is essential for lung function. This study found that $\mathrm{MC}_{\mathrm{TC}} \mathrm{S}$, but not $\mathrm{MC}_{\mathrm{T}} \mathrm{s}$, lead to abnormal formation of pulmonary microvascular endothelial structure both ex vivo and in vitro. Importantly, the activity of MC-specific proteases are necessary for the vasculodisruptive effects.

MCs can disrupt angiogenesis under pathologic conditions. ${ }^{22,26,37-48} \mathrm{MC}$ accumulation was observed in some BPD animal models, including hyperoxia challenged mice and rats. ${ }^{22} \mathrm{~A}$ study in pulmonary hypertension, which is often associated with $\mathrm{BPD}$, suggests that $\mathrm{MC}_{\mathrm{TC}} \mathrm{S}$ promote lung vascular remodeling. ${ }^{41}$ Interestingly, a recent BPD study found that MC-deficient mice are protected from air space damage by neonatal hyperoxia, which hints at the antiangiogenic effects of MCs under this condition ${ }^{22}$ The current ex vivo study provides direct evidence of the possible impairment $\mathrm{MC}_{\mathrm{TC}}$ accumulation can cause in the late-canalicular and early-saccular phase, during which 

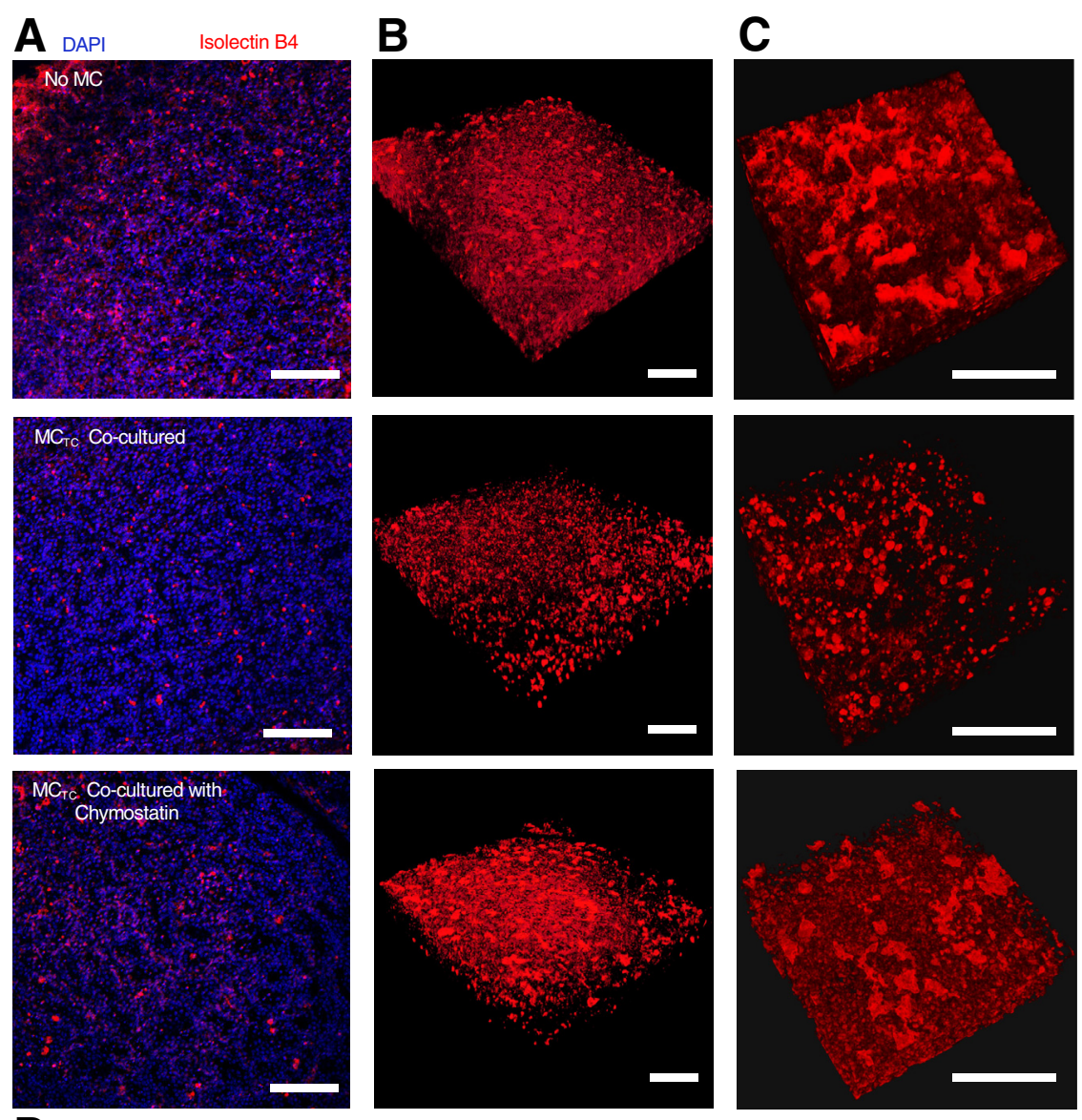

D

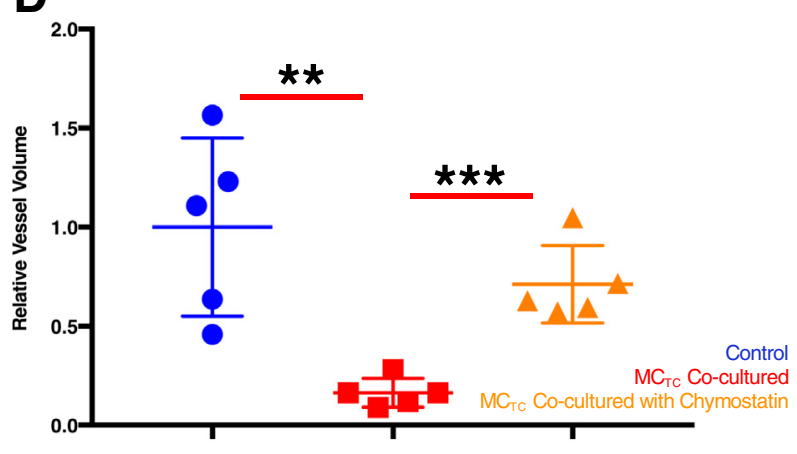

preterm infants are at high risk for BPD. ${ }^{2,4,9}$ Interestingly, a study in mice found that the presence of $\mathrm{MC}_{\mathrm{TC}} \mathrm{S}$ is important for the proper development of spinal cord vasculature. ${ }^{49} \mathrm{~A}$ different study in chicken lung also found that $\mathrm{MC}_{\mathrm{TC}} \mathrm{S}$ and $\mathrm{MC}_{\mathrm{T}} \mathrm{S}$ are recruited during embryonic development. ${ }^{50}$ However, $\mathrm{MC}_{\mathrm{TC}} \mathrm{S}$ are rarely found in healthy human lungs, and a mouse embryonic study found that MCs are not recruited to the healthy lung until after delivery. ${ }^{51}$ This evidence indicates that $\mathrm{MC}_{\mathrm{TC}} \mathrm{S}$ can facilitate vascular development and remodeling but do not contribute to normal human lung development.

Although $\mathrm{MC}_{\mathrm{TCs}}$ were clearly associated with a diminution in lung vascular structures ex vivo (Figures 1 and 6), it was noted that their presence had a biphasic effect on endothelial
Figure 6 Chymase inhibition protects against microvascular dysmorphism in the developing lung. A: Representative images of embryonic mouse lung tissue explant cultured for 48 hours alone [no mast cells (MCs) (control)] and with connective tissue phenotype mast cells $\left(M C_{T C}\right)$ or with $M C_{T C}$ pretreated with chymostatin. The microvasculature was stained with tetramethylrhodamine-conjugated isolectin B4 (red), and nuclei were stained with DAPI (blue). B: Representative three-dimensional reconstructed microvasculature in A. C: Representative three-dimensional reconstructed microvasculature showing higher magnification of a region in B. D: Quantification of total volume of vasculature relative to the total nuclear volume in each condition. $n=5$ (and in triplicates). ${ }^{* *} P<0.01$, ${ }^{* * *} P<0.001$ ( $t$-test). Scale bars $=100 \mu \mathrm{m}$. cell tube formation in vitro (Figures 2 and 5). This study quantified endothelial tube stability by measuring the time at which the cultures had $70 \%$ of maximal tube complexity. This decision was based on a careful evaluation of the timing and distribution of tubular structures (data not shown), suggesting the effect size was most evident at this level.

Disruption of cell-extracellular matrix and cell-cell interactions is reported to be involved in microvascular structure dysmorphism. ${ }^{52-54}$ The current study data suggest that $\mathrm{MC}_{\mathrm{TC}} \mathrm{S}$ caused a marked loss of CDH5 but spared many other surface proteins, such as the targets of isolectin B4 (Figure 4C). CDH5 is important for maintaining endothelial adherens junctions, which help to balance vascular quiescence and angiogenesis. The loss of surface CDH5 can lead to increased cell migration 
and proliferation. ${ }^{53}$ In fact, preliminary studies suggest that MCs can significantly enhance feHPMVC proliferation (data not shown), which is a phenotype consistent with tight junction impairment. Another recent study found that the loss of surface CDH5 on corneal microvascular endothelial cells leads to a microvasculature simplification, resembling the current study's in vitro phenotype. ${ }^{54}$

Our serine protease inhibitor experiments suggest that MC proteases, specifically CMA1, play an important role in disrupting angiogenesis (Figures 5 and 6). This finding is consistent with the previous in vivo study, which found that inhibition of CMA1 can protect against renal microvascular damage in the diabetic rat. ${ }^{55}$ CMA1, tryptase- $\alpha / \beta_{1}$ and tryptase- $\beta_{2}$ may affect angiogenesis through many different mechanisms. ${ }^{37,43,45,46}$ CMA1 can cleave angiotensin I, producing angiotensin II and promoting matrix metalloproteinase 9 maturation. MC serine proteases can also cleave membranebound stem cell factor (SCF), stimulating production of more $\mathrm{SCF}^{27,52}$ Our preliminary RT-qPCR analysis found a significant increase in feHPMVC SCF gene regulation (data not shown). This finding is partially supported by a study that found that SCF is a potent endothelial permeability factor that promotes internalization of CDH5 in mouse corneal model, ${ }^{52}$ which leads to corneal microvasculature dysmorphism.

There are limitations to the studies presented here. Although the effects of human MCs on human endothelial cells are studied here in vitro, LUVA does not recapitulate all aspects of human primary MCs. Likewise, our ex vivo mouse lung model lacks many of the complexities of the postnatal human lung. Moreover, mouse lung and human MC line (LUVA) co-culture can have potential histoincompatibility issues. This study used the transwell system with a $0.45-\mu \mathrm{m}$ filter size, which prevents the mouse lung and human $\mathrm{MC}$ line $\left(\mathrm{MC}_{\mathrm{TC}} \mathrm{LUVA}\right)$ from direct contact. This study also included $\mathrm{MC}_{\mathrm{T}} \mathrm{LUVA}$ as the second control, which helped rule out the possible phenotype due to histoincompatibility. However, these studies take advantage of using the mouse lung from the saccular stage of histologic development, the time when infants are at the greatest risk for BPD. ${ }^{3,9,30}$ Interestingly, DAPI staining of ex vivo lung tissue suggested changes in the overall structure of the parenchymal region in the presence of $\mathrm{MC}_{\mathrm{TC}} \mathrm{S}$. These changes may be a secondary effect of the vascular dysmorphia caused by $\mathrm{MC}_{\mathrm{TC}} \mathrm{S}$ or could be an independent and direct effect. This study did not quantify these changes because our system almost certainly does not recapitulate proper distal airspace structure or morphologic features. Testing the effects of $\mathrm{MC}_{\mathrm{TC}} \mathrm{S}$ directly on alveolar formation and structure should be directly tested in appropriate model systems and is one focus of our future studies.

\section{Acknowledgments}

We thank Dr. Siva K. Solletti, Dr. Ravi Misra, Christopher S. Slaunwhite, Kathy Donlon, Cory J. Poole, and Tristan
McRae for advice and experimental support; and Dr. Michael Welte, David S. Goldfarb, and Sina Ghaemmaghami for helpful discussions.

\section{Author Contributions}

Y.R., T.J.M., and J.P. designed the studies; J.A.M. and J.P. contributed reagents and experiment materials; Y.L. and S.W. established research protocols; Y.R. performed the studies; Y.R. and T.J.M. analyzed data; and Y.R. and T.J.M. wrote the manuscript; all authors approved the manuscript.

\section{Supplemental Data}

Supplemental material for this article can be found at http://doi.org/10.1016/j.ajpath.2020.04.017.

\section{References}

1. Abman SH, Bancalari E, Jobe A: The evolution of bronchopulmonary dysplasia after 50 years. Am J Respir Crit Care Med 2017, 195 421-424

2. Jobe AH: The new bronchopulmonary dysplasia. Curr Opin Pediatr 2011, 23:167-172

3. Stenmark KR, Abman SH: Lung vascular development: implications for the pathogenesis of bronchopulmonary dysplasia. Annu Rev Physiol 2005, 67:623-661

4. Kair LR, Leonard DT, Anderson JM: Bronchopulmonary dysplasia. Pediatr Rev 2012, 33:255-264

5. Baraldi E, Filippone M: Chronic lung disease after premature birth. $\mathrm{N}$ Engl J Med 2007, 357:1946-1955

6. Bose CL, Dammann CE, Laughon MM: Bronchopulmonary dysplasia and inflammatory biomarkers in the premature neonate. Arch Dis Child Fetal Neonatal Ed 2008, 93:F455-F461

7. Jo HS, Cho KH, Cho SI, Song ES, Kim BI: Recent changes in the incidence of bronchopulmonary dysplasia among very-low-birthweight infants in Korea. J Korean Med Sci 2015, 30(Suppl 1): S81-S87

8. Abman SH: Bronchopulmonary dysplasia. Am J Respir Crit Care Med 2001, 164:1755-1756

9. Bhatt AJ, Pryhuber GS, Huyck H, Watkins RH, Metlay LA, Maniscalco WM: Disrupted pulmonary vasculature and decreased vascular endothelial growth factor, Flt-1, and TIE-2 in human infants dying with bronchopulmonary dysplasia. Am J Respir Crit Care Med 2001, 164:1971-1980

10. Bhattacharya S, Go D, Krenitsky DL, Huyck HL, Solleti SK, Lunger VA, Metlay L, Srisuma S, Wert SE, Mariani TJ, Pryhuber GS: Genome-wide transcriptional profiling reveals connective tissue mast cell accumulation in bronchopulmonary dysplasia. Am J Respir Crit Care Med 2012, 186:349-358

11. Hallgren J, Gurish MF: Mast cell progenitor trafficking and maturation. Adv Exp Med Biol 2011, 716:14-28

12. Nilsson G, Dahlin JS: New insights into the origin of mast cells. Allergy 2019, 74:844-845

13. Grootens J, Ungerstedt JS, Nilsson G, Dahlin JS: Deciphering the differentiation trajectory from hematopoietic stem cells to mast cells. Blood Adv 2018, 2:2273-2281

14. Collington SJ, Williams TJ, Weller CL: Mechanisms underlying the localisation of mast cells in tissues. Trends Immunol 2011, 32: 478-485 
15. Cildir G, Pant H, Lopez AF, Tergaonkar V: The transcriptional program, functional heterogeneity, and clinical targeting of mast cells. J Exp Med 2017, 214:2491-2506

16. Dwyer DF, Barrett NA, Austen KF; Immunological Genome Project Consortium: Expression profiling of constitutive mast cells reveals a unique identity within the immune system. Nat Immunol 2016, 17 : $878-887$

17. Hsieh FH, Sharma P, Gibbons A, Goggans T, Erzurum SC, Haque SJ: Human airway epithelial cell determinants of survival and functional phenotype for primary human mast cells. Proc Natl Acad Sci U S A 2005, 102:14380-14385

18. Wernersson S, Pejler G: Mast cell secretory granules: armed for battle. Nat Rev Immunol 2014, 14:478-494

19. Xing W, Austen KF, Gurish MF, Jones TG: Protease phenotype of constitutive connective tissue and of induced mucosal mast cells in mice is regulated by the tissue. Proc Natl Acad Sci U S A 2011, 108 : 14210-14215

20. Galli SJ, Borregaard N, Wynn TA: Phenotypic and functional plasticity of cells of innate immunity: macrophages, mast cells and neutrophils. Nat Immunol 2011, 12:1035-1044

21. Dahlin JS, Hallgren J: Mast cell progenitors: origin, development and migration to tissues. Mol Immunol 2015, 63:9-17

22. Veerappan A, Thompson M, Savage AR, Silverman ML, Chan WS, Sung B, Summers B, Montelione KC, Benedict P, Groh B, Vicencio AG, Peinado H, Worgall S, Silver RB: Mast cells and exosomes in hyperoxia-induced neonatal lung disease. Am J Physiol Lung Cell Mol Physiol 2016, 310:L1218-L1232

23. Douaiher J, Succar J, Lancerotto L, Gurish MF, Orgill DP, Hamilton MJ, Krilis SA, Stevens RL: Development of mast cells and importance of their tryptase and chymase serine proteases in inflammation and wound healing. Adv Immunol 2014, 122:211-252

24. Gosman MM, Postma DS, Vonk JM, Rutgers B, Lodewijk M, Smith M, Luinge MA, Ten Hacken NH, Timens W: Association of mast cells with lung function in chronic obstructive pulmonary disease. Respir Res 2008, 9:64

25. Hansbro P, Beckett E, Stevens R, Jarnicki A, Kim R, Hanish I, Hansbro N, Deane A, Keely S, Horvat J, Yang M, Oliver B, van Rooijen N, Inman M, Adachi R, Soberman R, Hamadi S, Wark P, Foster P: A short-term model of COPD identifies a role for mast cell tryptase (P3242). J Immunol 2013, 190(1 Suppl):136.3

26. Soltani A, Ewe YP, Lim ZS, Sohal SS, Reid D, Weston S, WoodBaker R, Walters EH: Mast cells in COPD airways: relationship to bronchodilator responsiveness and angiogenesis. Eur Respir J 2012, 39:1361-1367

27. Berger P, Girodet PO, Begueret H, Ousova O, Perng DW, Marthan R, Walls AF, Tunon de Lara JM: Tryptase-stimulated human airway smooth muscle cells induce cytokine synthesis and mast cell chemotaxis. FASEB J 2003, 17:2139-2141

28. Thebaud B, Ladha F, Michelakis ED, Sawicka M, Thurston G, Eaton F, Hashimoto K, Harry G, Haromy A, Korbutt G, Archer SL: Vascular endothelial growth factor gene therapy increases survival, promotes lung angiogenesis, and prevents alveolar damage in hyperoxia-induced lung injury: evidence that angiogenesis participates in alveolarization. Circulation 2005, 112:2477-2486

29. Yao J, Guihard PJ, Wu X, Blazquez-Medela AM, Spencer MJ, Jumabay M, Tontonoz P, Fogelman AM, Bostrom KI, Yao Y: Vascular endothelium plays a key role in directing pulmonary epithelial cell differentiation. J Cell Biol 2017, 216:3369-3385

30. Herriges M, Morrisey EE: Lung development: orchestrating the generation and regeneration of a complex organ. Development 2014 141:502-513

31. Parera MC, van Dooren M, van Kempen M, de Krijger $\mathrm{R}$, Grosveld F, Tibboel D, Rottier R: Distal angiogenesis: a new concept for lung vascular morphogenesis. Am J Physiol Lung Cell Mol Physiol 2005, 288:L141-L149

32. Laidlaw TM, Steinke JW, Tinana AM, Feng C, Xing W, Lam BK, Paruchuri S, Boyce JA, Borish L: Characterization of a novel human mast cell line that responds to stem cell factor and expresses functional FcepsilonRI. J Allergy Clin Immunol 2011, 127:815-822. e1-5

33. Ye L, Martin TA, Parr C, Harrison GM, Mansel RE, Jiang WG: Biphasic effects of 17-beta-estradiol on expression of occludin and transendothelial resistance and paracellular permeability in human vascular endothelial cells. J Cell Physiol 2003, 196:362-369

34. Kubota SI, Takahashi K, Nishida J, Morishita Y, Ehata S, Tainaka K, Miyazono K, Ueda HR: Whole-body profiling of cancer metastasis with single-cell resolution. Cell Rep 2017, 20:236-250

35. Bankova LG, Dwyer DF, Liu AY, Austen KF, Gurish MF: Maturation of mast cell progenitors to mucosal mast cells during allergic pulmonary inflammation in mice. Mucosal Immunol 2014, 8:596

36. Kitamura Y, Shimada M, Hatanaka K, Miyano Y: Development of mast cells from grafted bone marrow cells in irradiated mice. Nature 1977, 268:442-443

37. de Souza Junior DA, Santana AC, da Silva EZ, Oliver C, Jamur MC: The role of mast cell specific chymases and tryptases in tumor angiogenesis. Biomed Res Int 2015, 2015:142359

38. Doggrell SA, Wanstall JC: Vascular chymase: pathophysiological role and therapeutic potential of inhibition. Cardiovasc Res 2004, 61: 653-662

39. He S, Aslam A, Gaca MD, He Y, Buckley MG, Hollenberg MD, Walls AF: Inhibitors of tryptase as mast cell-stabilizing agents in the human airways: effects of tryptase and other agonists of proteinaseactivated receptor 2 on histamine release. J Pharmacol Exp Ther 2004, 309:119-126

40. Heuston S, Hyland NP: Chymase inhibition as a pharmacological target: a role in inflammatory and functional gastrointestinal disorders? Br J Pharmacol 2012, 167:732-740

41. Hoffmann J, Yin J, Kukucka M, Yin N, Saarikko I, Sterner-Kock A, Fujii H, Leong-Poi H, Kuppe H, Schermuly RT, Kuebler WM: Mast cells promote lung vascular remodelling in pulmonary hypertension. Eur Respir J 2011, 37:1400-1410

42. Metcalfe DD, Mekori YA: Pathogenesis and pathology of mastocytosis. Annu Rev Pathol 2017, 12:487-514

43. Russo A, Russo G, Peticca M, Pietropaolo C, Di Rosa M, Iuvone T: Inhibition of granuloma-associated angiogenesis by controlling mast cell mediator release: role of mast cell protease-5. Br J Pharmacol 2005, 145:24-33

44. Theoharides TC, Valent P, Akin C: Mast cells, mastocytosis, and related disorders. N Engl J Med 2015, 373:163-172

45. de Souza Junior DA, Borges AC, Santana AC, Oliver C, Jamur MC: Mast cell proteases 6 and 7 stimulate angiogenesis by inducing endothelial cells to release angiogenic factors. PLoS One 2015, 10: e0144081

46. Wimazal F, Jordan J-H, Sperr WR, Chott A, Dabbass S, Lechner K, Horny HP, Valent P: Increased angiogenesis in the bone marrow of patients with systemic mastocytosis. Am J Pathol 2002, 160: $1639-1645$

47. Ribatti D, Nico B, Maxia C, Longo V, Murtas D, Mangieri D, Perra MT, De Giorgis M, Piras F, Crivellato E, Sirigu P: Neovascularization and mast cells with tryptase activity increase simultaneously in human pterygium. J Cell Mol Med 2007, 11:585-589

48. Vartio T, Seppä H, Vaheri A: Susceptibility of soluble and matrix fibronectins to degradation by tissue proteinases, mast cell chymase and cathepsin G. J Biol Chem 1981, 256:471-477

49. Dudeck A, Köberle M, Goldmann O, Meyer N, Dudeck J, Lemmens S, Rohde M, Roldán NG, Dietze-Schwonberg K, Orinska Z, Medina E, Hendrix S, Metz M, Zenclussen AC, von Stebut E, Biedermann T: Mast cells as protectors of health. J Allergy Clin Immunol 2019, 144(Suppl):S4-S18

50. Ribatti D, Contino R, Quondamatteo F, Formica V, Tursi A: Mast cell populations in the chick embryo lung and their response to compound 48/80 and dexamethasone. Anat Embryol 1992, 186:241-244

51. Abraham D, Oster H, Huber M, Leitges M: The expression pattern of three mast cell specific proteases during mouse development. Mol Immunol 2007, 44:732-740 
52. Kim JY, Choi JS, Song SH, Im JE, Kim JM, Kim K, Kwon S, Shin HK, Joo CK, Lee BH, Suh W: Stem cell factor is a potent endothelial permeability factor. Arterioscler Thromb Vasc Biol 2014, 34:1459-1467

53. Wallez Y, Vilgrain I, Huber P: Angiogenesis: the VE-cadherin switch. Trends Cardiovasc Med 2006, 16:55-59
54. Yamamoto H, Ehling M, Kato K, Kanai K, van Lessen M, Frye M, Zeuschner D, Nakayama M, Vestweber D, Adams RH: Integrin beta1 controls VE-cadherin localization and blood vessel stability. Nat Commun 2015, 6:6429

55. Takai S, Jin D, Miyazaki M: Multiple mechanisms for the action of chymase inhibitors. J Pharmacol Sci 2012, 118:311-316 